\title{
EDITORIAL
}

\section{RATIONALE AND LESSONS (TO BE) LEARNED FROM THE AUSTRIAN PRESIDENCY CONFERENCE ON 'IMPACT OF RESEARCH AND INNOVATION POLICY AT THE CROSSROADS OF POLICY DESIGN, IMPLEMENTATION AND EVALUATION'}

\author{
KLAUS SCHUCH, CENTRE FOR SOCIAL INNOVATION (ZSI) \& AUSTRIAN PLATFORM FOR RESEARCH AND \\ TECHNOLOGY POLICY EVALUATION (FTEVAL)
}

DOI: $10.22163 /$ fteval.2019.358

\section{DEAR READERS!}

$\mathrm{M}$ ost impact evaluations of R\&l policy interventions focus either on scientific-technical effects or on economic effects. For this purpose, suitable indicators, data bases and methods have been created and continuously developed in recent decades. However, the comprehensibility and assessment of social and societal effects of Ryl policy interventions has only recently gained new attention. One reason for this is the orientation of R\&l policy towards major societal challenges ('new mission-oriented Rgl policy'l). The European Commission's "Horizon Europe", the 9 $9^{\text {th }}$ European Research and Innovation Framework Program, explicitly provides within the second pillar of the next Framework Program specific R\&D missions still to be selected. For these missions as well as for the global challenges postulated in Horizon Europe - as in Horizon 2020 - the social impact dimension is highly relevant as it explicitly addresses the goals set by society (for example, the United Nations Sustainable Development Goals / SDGs ${ }^{2}$. In order to better track and measure the impact dimensions of Horizon Europe, an expert report ${ }^{3}$ was presented immediately after the publication of the European Commission's proposal for Horizon Europe in July 2018, which distinguishes between the following three impact dimensions: (1) scientific impact, (2) societal impact and (3) economic impact. Already the year before, an ERAC ad-hoc working group submitted a report ${ }^{4}$ that also argues for different dimensions of impact, but focuses on measuring the impact of European framework programs at national level.
In anticipation of developments at the European level, the Austrian Federal Ministry of Transport, Innovation and Technology suggested in 2017 to hold an international conference for the measurement of mission-oriented Ryl interventions within the framework of the Austrian Council Presidency. The Austrian Platform for Research and Technology Policy Evaluation (fteval) was commissioned with this task and organised the conference in November 2018 together with the Manchester Institute of Innovation Research and the Institut Francilien Recherche, Innovation et Société from Paris. The starting point for the conference was that, first and foremost, not only the European, but also national Rql policies are required to make a contribution to society and to document the corresponding effects, and second, that the new impact agenda has an impact on the whole policy cycle, including policy-making, policy implementation and policy evaluation.

Both the presidency event and the expert report of the European Commission have chosen the approach of impact pathways to further discuss the measurement of the three different dimensions of impact in order to emphasize the design and process character of effect creation and effect development. In particular, the impact pathways for measuring societal effects are challenging. These are confronted with basic definitional problems. While "social impact" in the EU context is understood as a generic term (e.g. in the case of the Better Regulation Toolbox of the European Commission), which implies effects on society, politics, 
environment, economy and other dimensions, "societal impact" is understood as more specifically. Also, the approaches and models commonly used in the scientific literature to establish social impact of Ryl policies refer to a variety of issues, including policy implications, and lack clear demarcations ${ }^{5}$. So far, existing assessments of the social impact of R\&l policy interventions are often only contextual and specific as well as qualitative and anecdotal in nature.

In addition to the theoretical problems of demarcation, there are serious deficits with regard to the indicators for assessing societal effects of RqI policies as well as a lack of systematically collected, quality-assured data. Moreover, there is often a falsely equation of social impact with dissemination or transfer, to which most of the so-called alternative metrics (altmetrics) focus. Particular challenges for the development of appropriate indicators to measure societal impact include

1. that the time taken to achieve the actual impact on society is longer than the achievement of concrete results;

2. that the assignment of social changes is more difficult than the assignment of scientific references or economic attributes;

3. that the availability and comparability of data to track social and political impacts of $R \& 1$ interventions is severely limited.

According to the literature review ${ }^{6}$ in the European Commission's expert report, specific and commonly used indicators for measuring social impact are almost non-existent, or if so, often only as suggestions without systematic application? ${ }^{7}$. It is therefore hardly surprising that most agencies and evaluation projects do not consider the social (or societal) impact of Ryl. In a few cases, societal impact in ex-ante evaluations is sometimes cited as a criterion to consider, but without specific indicators.

The Austrian Council Presidency Conference 'Impact of Research and Innovation Policy at the Crossroads of Policy Design, Implementation and Evaluation' has therefore addressed the question of how impacts along the three dimensions of impact mentioned above (scientific, economic and social) can be better understood, designed and measured by a favorable R\&I policy. The conference structured the topic impact evaluation into four blocks:

1. The essence of impact-oriented R\&I policy

2. Design, implementation and support measures for an impactoriented RqI policy

3. Novel concepts, tools and methods for assessing social impact of R\&I policies and

4. Effects of impact evaluations on policy learning

These topics were addressed in five key-note presentations, four panel discussions, seven specific paper sessions featuring 40 ex-ante selected papers, three workshops, a case study on impact measurement at the French National Agricultural Research Institute and a poster session, in which 11 posters were presented.

296 experts from 39 countries and all continents have registered for the conference. Of these, 255 actually attended the conference. 131 of the accredited persons can be assigned to the research area, 73 came from agencies, 70 from politics, 13 from intermediary institutions including research infrastructures, 8 from the business enterprise sector and one from the press. $42 \%$ of the participants came from Austria. Larger contingents came from the category "International Institutions" ( $\mathrm{n}=$ 24), especially from the European Commission, but also from OECD, EUREKA and COST, which made the European dimension of the event visible. 21 of the accredited persons came from Germany; 17 from the UK; 10 from France and Norway; 9 from Belgium and Spain and 8 from the Netherlands. With the exception of Malta, Slovakia and Slovenia, all EU countries were represented. More accredited persons from non-EU countries came from Iceland, Norway, Russia, Switzerland, Ukraine, and from Australia, Brazil, Chile, Iran, Japan, Nepal, South Africa and the United States.

Feedback on the conference was consistently positive. 93\% said that the organization was very good or good; $97 \%$ would recommend the conference.

Overall, the conference could contribute to the following immediate results:

- The level of knowledge about impact evaluations in the Rql area has been widely consolidated.

- Recent experiments to promote effective policies and measures have been put forward for discussion.

- Methodological experiences to better assess the social impact of mission-oriented R\&I policy have been extensively shared.

- Indicators to measure progress on key pathways or actual impact in the short, medium and long term were presented and reflected.

- An increased use of more comprehensive impact assessment approaches in the field of Ryl policy was suggested.

- The need to use unique identifiers and better data bases was discussed.

- Awareness was raised for the use and impact of big data approaches and artificial intelligence for text mining, automated data collection, and automated data analysis.

- The need for clear expectation management was recognized.

- It has been widely acknowledged that for impact assessment, both research organizations and agencies themselves should set up appropriate procedural arrangements to support societal impacts and to document them.

These conference proceedings collect 21 papers and 11 posters presented and discussed during the conference.

I am very grateful to all authors who contributed to these conference proceedings and to the success of the conference!

\section{Yours sincerely}

\section{Klaus Schuch}

Executive Manager of the Austrian Platform for Research and Technology Policy Evaluation 


\section{LITERATURE}

Barre, R. (2010): Towards Socially Robust S\&T Indicators: Indicators as Debatable Devices, Enabling Collective Learning', Research Evaluation, 19(3), 227-31.

Brewer, J. (2011): The impact of impact. Research Evaluation; 20(3), 255-256, https://doi.org/10.3152/095820211X12941371876869.

ERAC (2017): Final Report of the ERAC Ad-hoc Working Group on Measuring the Impact of EU Framework Programmes for Research and Innovation at National Level, ERAC 1206/17.

Flecha, R. (2018): A Note on Key Concepts for Social Impact of Research Assessment. https://archive.org/details/ANoteOnKeyConceptsForSociallmpactOfResearchAssessment.

Gassler, H., Polt, W., und Rammer, C. (2006): Schwerpunktsetzungen in der Forschungs- und Technologiepolitik - eine Analyse der Paradigmenwechsel seit 1945, Österreichische Zeitschrift für Politikwissenschaft (ÖZP), 35(1), 7-23.
Raua, H., Gogginsb, G. und Fahyb, F. (2018): From invisibility to impact: Recognising the scientific and societal relevance of interdisciplinary sustainability research, Research Policy, 47, 266-276.

Reale, E., Avramov, D., Canhial, K., Donovan, C., Flecha, R., Holm, P. und Van Horik, R. (2017): A review of literature on evaluating the scientific, social and political impact of social sciences and humanities research, Research Evaluation, January, 1-11.

Van den Besselaar, P., Flecha, R. und Radauer, A. (2018): Monitoring the Impact of EU Framework Programmes, Expert Report, Publications Office of the European Union: Luxembourg.

\section{THE ahead

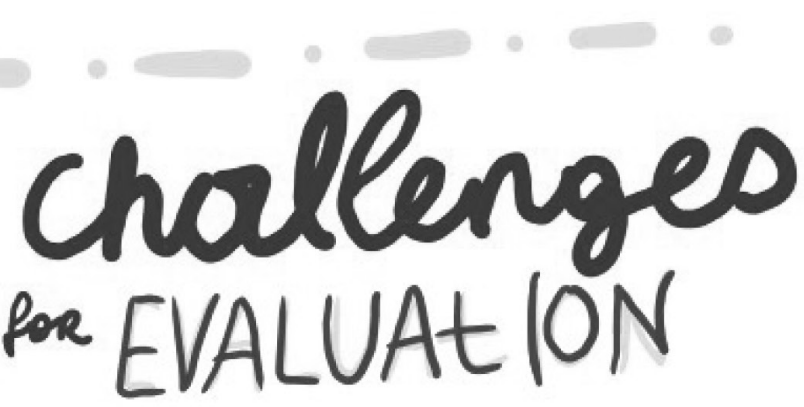

\section{MANAGE EXPECTATIONS}

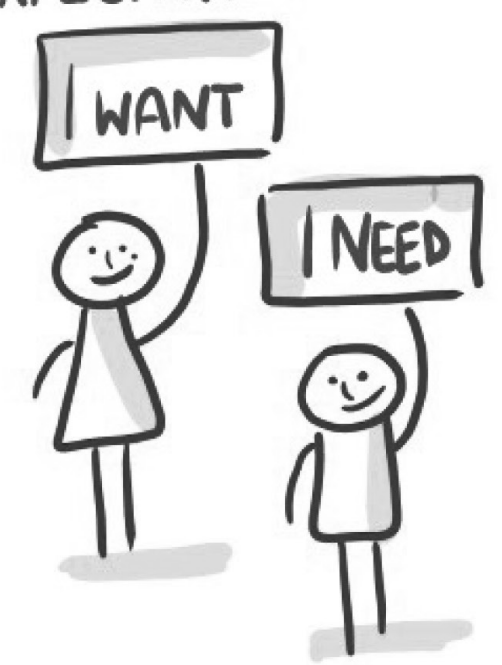

